Ciência Florestal, Santa Maria, v. 22, n. 2, p. 331-341, abr.-jun., 2012

ISSN 0103-9954

\title{
RENDIMENTO VOLUMÉTRICO E ENERGÉTICO DE CLONES DE HÍBRIDOS DE Eucalyptus sp. NO POLO GESSEIRO DO ARARIPE, PE
}

\author{
VOLUMETRIC AND ENERGY EFFICIENCY OF HYBRIDS CLONES OF \\ Eucalyptus sp. IN THE GYPSUM POLE OF ARARIPE, PERNAMBUCO STATE
}

Fernando Henrique de Lima Gadelha ${ }^{1}$ José Antônio Aleixo da Silva ${ }^{2}$ Rinaldo Luiz Caraciolo Ferreira ${ }^{3}$ Ivan Vieira de Melo ${ }^{4}$ Danillo Lobo Jorge ${ }^{5}$ José Alves Tavares ${ }^{6}$ Sergio Peres Ramos da Silva ${ }^{7}$

\section{RESUMO}

O presente trabalho teve como objetivo avaliar o rendimento volumétrico e energético produzido por três diferentes clones de híbridos de Eucalyptus sp.: C39 Híbrido de Eucalyptus urophylla (cruzamento natural); C41 Híbrido de Eucalyptus urophylla (cruzamento natural) e C11 Híbrido de Eucalyptus brassiana (cruzamento natural). Para a quantificação do volume de madeira foi utilizado o processo de cubagem rigorosa pelo método de Smalian. A densidade básica da madeira e o poder calorífico foram determinados, respectivamente pelas normas ABNT (1984 e 2003). O consumo de lenha foi obtido por meio do acompanhamento da calcinação da gipsita. O delineamento utilizado no experimento foi o inteiramente aleatório. As produtividades volumétricas de tais clones foram, respectivamente, 158,46, 132,20 e 164,89 $\mathrm{m}^{3} /$ ha aos 7,5 anos de idade, apresentando rendimentos durante a calcinação da gipsita de $0,16,0,10$ e 0,13 metros cúbicos de lenha por tonelada de gesso produzida, quando a lenha foi utilizada em forma de toras. Para a lenha em cavacos os rendimentos foram de 0,11, 0,08 e 0,09 metros cúbicos por tonelada de gesso, resultados bem acima dos melhores rendimentos da lenha de vegetação nativa, que são de 0,16 metros cúbicos por tonelada.

Palavras-chave: Polo Gesseiro do Araripe; eucaliptocultura; demanda energética.

\section{ABSTRACT}

This study aimed to evaluate the volumetric efficiency and energy produced by three different hybrid clones of Eucalyptus sp. C39 Hybrid Eucalyptus urophylla (natural crossing); C41 Hybrid Eucalyptus urophylla (natural crossing) and C11 Hybrid Eucalyptus brassiana (natural crossing). The Smalian method was used to quantify the volume of wood. The basic wood density and the calorific value were determined in accordance with their respective Brazilian Association of Technical Standards (1984 and 2003). The firewood consumption was obtained through the monitoring the calcination of gypsum. The statistical analysis was done considering a complete randomized design. The volumetric productivity of these 7.5 year-old clones were $158.46,132.20$ and $164.89 \mathrm{~m}^{3} /$ ha, respectively. The amount of wood cubic meters, in

1. Engenheiro Florestal, Msc., Doutorando, Programa de Pós-Graduação em Ciências Florestais, Universidade Federal Rural de Pernambuco, Rua Dom Manoel de Medeiros, s/n, Bairro Dois Irmãos, CEP 52171-900, Recife (PE).limagadelha@gmail.com

2. Engenheiro Agrônomo, Ph.D., Professor Associado, Universidade Federal Rural de Pernambuco, Rua Manoel de Medeiros, s/n, Dois Irmãos, CEP 52171-900, Recife (PE). jaaleixo@uol.com.br

3. Engenheiro Florestal, Dr., Professor Associado, Universidade Federal Rural de Pernambuco, Rua Manoel de Medeiros, s/n, Dois Irmãos, CEP 52171-900, Recife (PE). rinaldo@dcfl.ufrpe.br

4. Engenheiro Mecânico, Dr., Professor Adjunto, Universidade Federal de Pernambuco, Avenida Prof ${ }^{0}$ Moraes Rego s/n, Cidade Universitária, CEP 50740-530, Recife (PE). ivan.melo@uol.com.br

5. Graduando em Engenharia Florestal, Universidade Federal Rural de Pernambuco, Rua Dom Manoel de Medeiros, s/n, Bairro Dois Irmãos, CEP 52171-900, Recife (PE). dlj.ufrpe@hotmail.com

6. Engenheiro Agrônomo, Pesquisador, Instituto Agronômico de Pernambuco, Estação Experimental de Araripina, CEP 56280-000,Araripina (PE).

7. Engenheiro Mecânico e Químico Industrial, Ph.D., Professor, Universidade de Pernambuco, Escola Politécnica Coordenador do Laboratório de Combustíveis e Energia (POLICOM), Rua Benfica, 455, Bairro Madalena, CEP 50750-470, Recife (PE). speres@upe.poli.br

Recebido para publicação em 19/04/2010 e aceito em 05/08/2011 
form of logs, necessary for the calcinations of one ton of gypsum was $0.16,0.10$ and 0.13 . However, when wood chips were used, quantities used were $0.11,0.08$ and 0.09 cubic meters per ton. These results of the calcination efficiency using wood chips were better than the best result obtained using the wood of native vegetation that was 0.16 cubic meters per ton.

Keywords: Gypsum Pole; growing eucalyptus; energy demand.

\section{INTRODUÇÃO}

O grande destaque da Chapada do Araripe, onde se localiza o Arranjo Produtivo Local (APL) do Polo Gesseiro do Araripe, é a sua produção de gipsita para industrialização do gesso, cujas jazidas principais estão nos municípios de Araripina, Ipubi, Trindade, Bodocó e Ouricuri, de onde saem $95 \%$ de todo o gesso consumido no Brasil (ALBUQUERQUE, 2002). Esta região apresenta precipitação média anual de $760 \mathrm{~mm}$, concentrada entre os meses de novembro a maio, representando mais de $80 \%$ do total anual, o que provoca deficiências hídricas que se acumulam a partir do mês de maio até o mês de outubro, quando essa é mínima, sendo atenuada nos meses de fevereiro a abril, nos quais ocorre um pequeno excesso (ITEP/LAMEPE, 2009). O clima é do tipo Bshw', semiárido, quente, com chuvas de verão-outono, pela classificação de Koppen. A temperatura média anual é de $24^{\circ} \mathrm{C}$ (ARAÚJO, 2004). O solo é do tipo Latossolo amarelo (EMBRAPA SOLOS, 2006).

De acordo com Lyra Sobrinho (2007), a matriz energética constitui um dos principais gargalos ao desenvolvimento do setor gesseiro no Estado de Pernambuco. O setor de produção secundária, no qual se enquadram as calcinadoras do Araripe, consome, predominantemente, a biomassa florestal como fonte energética, além de óleo BPF (Baixo Poder de Fluidez), cujo preço oscila de acordo com os preços dos derivados de petróleo. A constante variação no preço do óleo BPF fez com que as empresas migrassem para o consumo de lenha, aliado a outros fatores incentivadores como a precária fiscalização de combate a comercialização de lenha ilegal.

A substituição da lenha da mata nativa por lenha de reflorestamento, com espécies de rápido crescimento, apresenta-se como uma alternativa econômica e ambientalmente viável. Apesar das inúmeras espécies arbóreas existentes, o eucalipto, em função de sua grande plasticidade ambiental, altos índices de produtividade, ampla diversidade de espécies e características energéticas (densidade da madeira e poder calorífico), é o gênero mais utilizadas para a implantação de florestamento e reflorestamentos com fins energéticos (COUTO e MULLER, 2000; MORA e GARCIA, 2000).

A implantação de florestas com finalidades energéticas, remonta ao início do século passado, época inicial da silvicultura de florestas plantadas no Brasil. Isso se deu com o objetivo de atender à demanda por lenha, que na época já era material escasso no mercado (BALLONI et al., 1980). Atualmente, por meio do melhoramento genético e das técnicas de propagação por clones, as florestas energéticas de eucaliptos têm alcançado melhorias significativas quanto ao incremento médio anual em volume e quanto às características energéticas da madeira (BINKLEY e STAPE, 2004). De acordo com Müller e Couto (2006), o uso da madeira como fonte de energia é uma tendência mundial e a motivação para tal é a necessidade de diminuir o uso de combustíveis fósseis, tornando-se menos dependente dos países exportadores e reduzindo as emissões de gases nocivos à atmosfera.

Devido às restrições econômicas, ambientais e da dificuldade de substituição de combustíveis fósseis, evidenciou-se a relevância do estudo da aplicação de eficiência energética em todos os níveis de produção, distribuição e consumo (ATECEL, 2006). Diante do exposto, o presente trabalho teve como objetivo avaliar o rendimento volumétrico e energético produzido por três diferentes clones de híbridos de Eucalyptus sp., testados na Região do Polo Gesseiro de Pernambuco, usados como combustível, nas formas de lenha em toras e cavacos, em fornos para calcinação de gipsita.

\section{MATERIAL E MÉTODO}

A pesquisa foi realizada na indústria Gesso Aliança do Araripe Ltda., localizada na Rod. PE 630 s/n, km 02, Zona Rural e na indústria Gesso São Geraldo Ltda., localizada na Rod. BR 316 s/n, km 56, ambas na cidade de Trindade - PE.

A madeira usada na pesquisa foi oriunda de um experimento em andamento na Estação Experimental de Araripina, pertencente ao Instituto Agronômico de Pernambuco - IPA, localizado no 
Município de Araripina, semiárido pernambucano. Os testes de consumo de lenha em toras, para a calcinação da gipsita, foram realizados na Indústria Gesso Aliança do Araripe Ltda., enquanto que os testes para o consumo de lenha em cavacos foram desenvolvidos na empresa Gesso São Geraldo Ltda., em fornos semelhantes.

A madeira foi proveniente de um experimento inteiramente aleatório, com 4 repetições e parcelas de forma retangular $(14 \mathrm{~m} \mathrm{x}$ $21 \mathrm{~m}$ ), com 49 árvores, sendo mensuradas as 25 árvores da área útil da parcela (desconsiderando a bordadura). O experimento foi implantado no início do mês de março de 2002, com espaçamento de $3 \mathrm{x}$ $2 \mathrm{~m}$. Os dados foram coletados em outubro de 2009, configurando assim um povoamento com 7,5 anos de idade.

Para a realização da pesquisa foram escolhidos os clones dos híbridos C11 (Híbrido de Eucalyptus brassiana - cruzamento natural), C39 (Híbrido de Eucalyptus urophylla - cruzamento natural) e C41 (Híbrido de Eucalyptus urophylla - cruzamento natural), considerados como mais produtivos de acordo com análises realizadas por Silva (2008).

Após o corte, todas as árvores foram cubadas rigorosamente, pelo método de Smalian (MACHADO e FIGUEIREDO FILHO, 2003).

Para determinar a densidade básica da madeira foram seguidos os procedimentos recomendados pela norma NBR 11941 (ABNT, 2003), amostrando-se quatro indivíduos por tratamento, e as análises foram realizadas no Laboratório de Química da Madeira da Universidade Federal de Lavras - MG.

O PCS (Poder Calorífico Superior) foi determinando de acordo com a norma NBR 8633 (ABNT, 1984) e o manual do calorímetro de marca IKA, modelo C 2000, sendo amostrados cinco indivíduos por tratamento. Enquanto que o PCI (Poder Calorífico Inferior) foi determinado usando titulação química, conforme procedimento constante no manual do calorímetro e calculado pelo próprio calorímetro. As análises foram realizadas no POLICOM - Laboratório de Combustíveis e Energia da Universidade de Pernambuco.

A verificação do consumo de lenha, durante a calcinação da gipsita, teve início após o prévio aquecimento do forno, que foi carregado com a lenha de cada tratamento/clone, dando início à fornada. A partir desse momento, procedeu-se ao carregamento dos cilindros de calcinação com gipsita triturada. No momento em que foi detectada a completa calcinação da gipsita o abastecimento de lenha foi cortado. Após esse procedimento, foi contabilizada quantidade de gesso produzida e a quantidade de lenha consumida no processo. A lenha foi utilizada em toras de 1 metro e em cavacos com dimensão média de $5 \times 3 \mathrm{~cm}$, triturada em um picador de madeira.

De posse das informações de consumo de lenha, foi realizada uma simulação das áreas de plantio anual necessárias para tornar uma indústria de pequeno porte ( 2 mil toneladas de gesso/ mês) autossuficiente. Considerou-se a equação de Schumacher e Hall ajustada por Silva (2008) para o mesmo experimento e dados de diâmetro na altura do peito e altura total aos 4,5, 5,5 e 7,5 anos, com a finalidade de verificar o comportamento da curva de incremento médio anual em volume para os híbridos avaliados.

Para a realização das análises estatísticas, foi considerado um delineamento inteiramente ao acaso, com o objetivo analisar o comportamento dos tratamentos quanto às variáveis DBM, PCI, consumo de lenha e produção de gesso. Para a comparação das médias, foi utilizado o teste de Tukey a nível de $5 \%$ de probabilidade e o software utilizado para a avaliação estatística foi o Assistência Estatística ASSISTAT 7.5 BETA (SILVA e AZEVEDO, 2002).

\section{RESULTADOS E DISCUSSÃO}

\section{Rendimento Volumétrico}

A produtividade por hectare aos 7,5 anos (Tabela 1) variou de 132,20 a $164,89 \mathrm{~m}^{3} / \mathrm{ha}$ com média de $151,85 \mathrm{~m}^{3} / \mathrm{h}$. Os clones C41 e C11, apesar da taxa de mortalidade elevada, $15 \%$ e $13 \%$, respectivamente, consideradas altas se comparadas aos atuais padrões adotados em reflorestamentos de eucaliptos no Brasil $(\leq 10 \%)$, obtiveram uma produtividade semelhante ao clone $\mathrm{C} 39$, que teve uma taxa de sobrevivência de $97 \%$.

Mesmo com taxa de mortalidade alta, o clone $\mathrm{C} 11$ obteve o melhor rendimento, juntamente, com o clone C39. Provavelmente, uma maior disponibilidade de espaço entre plantas ocasionou um crescimento diferenciado para o clone (Tabela 1).

Porém, a taxa de mortalidade obtida no referido experimento pode ser facilmente diminuída, já que os valores apresentados ocorreram devido ao ataque de formigas cortadeiras na época de plantio, em que o combate realizado não foi, suficientemente, 
TABELA 1: Volume por planta (Vol/plt), taxa de sobrevivência (Sob), volume por hectare $\left(\mathrm{m}^{3} / \mathrm{ha}\right)$, incremento médio anual (IMA), da madeira de híbridos de Eucalyptus sp., no Polo Gesseiro do Araripe.

TABLE 1: Volume per plant (Vol / plt), survival rate $(\mathrm{Su})$, volume per hectare $\left(\mathrm{m}^{3} / \mathrm{ha}\right)$, mean annual increment (MAI), of wood and hybrids of Eucalyptus sp. in the Gypsum Pole of Araripe.

\begin{tabular}{ccccc}
\hline Trat/ Híbrido & Vol $/$ plt $\left(\mathrm{m}^{3}\right)$ & Sob. $(\%)$ & Vol $\left(\mathrm{m}^{3} / \mathrm{ha}\right)$ & IMA $\left(\mathrm{m}^{3} / \mathrm{ha} / \mathrm{ano}\right)$ \\
\hline T 7/C 39 & 0,0980 & 97 & 158,46 & 21,10 \\
T11/C 41 & 0,0933 & 85 & 132,20 & 17,62 \\
T15/C 11 & 0,1137 & 87 & 164,89 & 21,98 \\
\hline Médias & 0,1016 & 90 & 151,85 & 20,23 \\
\hline
\end{tabular}

eficaz. Tal situação pode ser explicada pelo comportamento das formigas cortadeiras, pertencentes aos gêneros Atta e Acromyrmex, que mostram preferências por algumas espécies vegetais desfolhando, constantemente, as mudas, enquanto plantas de outras espécies, não são atacadas, mesmo estando próximas ao ninho (BORBA, 2006).

Os incrementos médios anuais (IMA's) apresentados (Tabela 1) são menores que os estimados por Silva (2008) para o mesmo experimento aos 5,5 anos, indicando que aos 7,5 anos o povoamento já passou do ponto ótimo de corte, consequentemente, diminuindo o IMA.

Avaliando o desenvolvimento de um povoamento de Eucalyptus camaldulensis, plantado no espaçamento de $3 \times 2$ metros, numa área de cerrado no Estado de Minas Gerais, Oliveira et al. (1998) verificaram uma produtividade de $123,37 \mathrm{~m}^{3} /$ ha aos 6,5 anos, gerando um incremento médio anual de $17,62 \mathrm{~m}^{3} /$ ha. Enquanto que a pesquisa realizada por Gomide et al. (2005), com objetivo de avaliar a qualidade de novos clones inseridos pelas empresas florestais do Brasil, foi observado que aos sete anos pós-plantio o incremento médio anual variou de 33,9 a 52,9, com média de $44,5 \mathrm{~m}^{3} / \mathrm{ha} /$ ano. Já Binkley e Stape (2004) informaram que a produtividade média nacional de povoamentos clonais de eucaliptos é de $40 \mathrm{~m}^{3} / \mathrm{ha}$ /ano.

De acordo com o exposto, observa-se que os resultados encontrados nesta pesquisa são, em média, menores que a produtividade média nacional dos povoamentos de eucaliptos, porém, se comparados à produtividade de $4,5 \mathrm{~m}^{3} / \mathrm{ha} / \mathrm{ano}$, apresentada pelo MMA/SECTMA (2007) para a vegetação nativa da região onde foi realizado o estudo, esses valores se tornam mais expressivos. Deve-se considerar também que na pesquisa foi analisado um único espaçamento $(3 \times 2 \mathrm{~m})$ e que o espaçamento influencia diretamente na produtividade florestal (ALCORN, 2007).
Ainda é possívelverificar que a produtividade dos clones de eucaliptos foi superior aos resultados encontrados por Barros (2009), que avaliou uma área de caatinga sob o regime de manejo florestal em Trindade - PE aos sete anos e o IMA foi de 2,24 $\mathrm{m}^{3} /$ ha/ano e que a produtividade de áreas plantadas com sabiá (Mimosa caesalpiniefolia), jurema (Mimosa tenuiflora) e angico (Anadenanthera columbrina), também na Chapada do Araripe, aos 6,5 anos foi de $8,04,6,58$ e $5,64 \mathrm{~m}^{3} / \mathrm{ha} /$ ano, respectivamente. O mesmo acontece quanto às informações apresentadas por Riegelhaupt (2007) sobre a produtividade de Planos de Manejo Florestal na Caatinga, que indicaram um incremento médio anual entre 1,5 e 5 $\mathrm{m}^{3}$, com rotações que variam entre 10 e 15 anos.

\section{Densidade básica da madeira - DBM}

Na Tabela 2 é apresentada a análise de variância da DBM (Densidade Básica da Madeira) dos clones de híbridos de eucaliptos, em que foram verificadas diferenças significativas entre os tratamentos.

Na Tabela 3 pode-se observar a comparação de médias pelo Teste de Tukey da DBM. O clone C11 diferiu estatisticamente, quando comparado aos clones C41 e C39, enquanto que os clones C41 e C39 são estatisticamente semelhantes.

Os valores encontrados na pesquisa são maiores que os apresentados por Arango Alzate et al. (2005), onde foram avaliados quinze clones de Eucalyptus grandis, Eucalyptus saligna e Eucalyptus grandis $\times$ urophylla, aos 96 meses e se observou uma densidade básica média de 0,460, 0,470 e 0,490 $\mathrm{g} / \mathrm{cm}^{3}$, respectivamente, e estão dentro da amplitude encontrada por Sturion et al. (1987) que avaliou doze espécies de eucaliptos aos 126 meses e observou que a densidade básica da madeira variou entre $0,525 \mathrm{e}$ $0,715 \mathrm{~g} / \mathrm{cm}^{3}$.

Santana (2009) avaliando as propriedades energéticas de um clone híbrido de Eucalyptus 
TABELA 2: Análise de Variância da densidade básica da madeira dos clones de híbridos de Eucalyptus sp. TABLE 2: Analysis of variance of basic wood density of the Eucalyptus sp. hybrid clones.

\begin{tabular}{ccccc}
\hline F. V. & G. L. & S. Q. & Q. M. & F \\
\hline Clones & 2 & 0,02062 & 0,01031 & $56,5091^{*}$ \\
Resíduo & 6 & 0,00109 & 0,00018 & \\
\hline Total & 8 & 0,02171 & & \\
\hline
\end{tabular}

Em que: * significativo ao nível de 5\% de probabilidade

TABELA 3: Comparação de médias da densidade básica da madeira pelo teste de Tukey dos clones de híbridos de Eucalyptus sp.

TABLE 3: Mean of the basic wood density by Tukey test clones of the Eucalyptus sp. hybrid clones.

\begin{tabular}{cc}
\hline Trat/Clone & Média $\left(\mathrm{g} / \mathrm{cm}^{3}\right)$ \\
\hline T15/C11 & $0,633 \mathrm{a}$ \\
T11/C41 & $0,542 \mathrm{~b}$ \\
T7/C39 & $0,524 \mathrm{~b}$ \\
Média & 0,566 \\
CV $(\%)$ & 2,38 \\
\hline
\end{tabular}

Em que: As médias seguidas pela mesma letra não diferem estatisticamente entre si o teste de Tukey ao nível de $5 \%$ de probabilidade.

grandis $\times$ Eucalyptus urophylla, observou uma densidade básica da madeira de $0,452 \mathrm{~g} / \mathrm{cm}^{3}$ aos 7 anos, valor $20 \%$ menor ao apresentado neste trabalho.

Comparando estes resultados com os encontrados por Alves (2007) aos 4,5 anos para o mesmo experimento, para DBM foi obtida um incremento positivo de 7,5\% para o $\mathrm{C} 11$ e de $5 \%$ para os clones C41 e C39. Variações semelhantes foram encontradas na determinação da densidade básica da madeira de Eucalyptus urophylla aos 4 e aos 7 anos de idade (TRUGILHO, 2009).

\section{Determinação do poder calorífico inferior - PCI}

$\mathrm{Na}$ Tabela 4 apresenta-se a análise de variância para o PCI dos clones de híbridos de eucaliptos, sendo verificadas diferenças significativas entre os tratamentos.

$\mathrm{Na}$ comparação de médias pelo teste de Tukey, pode-se observar que a diferença estatística ocorreu apenas entre os tratamentos $\mathrm{T} 15 / \mathrm{C} 11$, que obteve PCI médio de $4.601,50 \mathrm{kcal} / \mathrm{kg}$ e o T7/C39 com média de 4.268,79 kcal/kg (Tabela 5).

Avaliando nove espécies do gênero
Eucalyptus, Brito et al. (1983) verificaram que o poder calorífico inferior para as espécies estudadas Variou de 4.409 a $4.699 \mathrm{kcal} / \mathrm{kg}$, com média de $4.570 \mathrm{kcal} / \mathrm{kg}$. Enquanto que Carvalho e Nahuz (2001), estudando a madeira do híbrido Eucalyptus grandis $\times$ Eucalyptus urophylla para uso como lenha, observaram um valor médio de 4078,87 $\mathrm{kcal} / \mathrm{kg}$. Mostrando que os resultados apresentados nesta pesquisa são semelhantes aos encontrados na literatura e, segundo Carvalho e Nahuz (2001), demonstram que a madeira produzida tem capacidade para ser usada na geração de energia.

\section{Consumo de lenha em toras}

De acordo com a análise da variância, para o consumo de lenha em toras e a produção de gesso, não existem diferenças significativas ao nível de $5 \%$.

Os resultados encontrados estão apresentados na (Tabela 6) e as variações entre consumo de lenha e produção de gesso podem ser justificadas pelos valores de densidade básica da madeira (Tabela 3), pelo teor de umidade da mesma no momento da queima e pelo poder calorífico útil, já que o híbrido C39, além de possuir a menor densidade básica da madeira dentre os clones testados, apresentou, no momento do teste, maior teor de umidade enquanto que o híbrido C41 apresentou menor teor de umidade e possui uma maior densidade básica da madeira.

De acordo com os testes realizados por Barros (2009), na mesma indústria e no mesmo forno, os rendimentos para a lenha de sabiá (Mimosa caesalpiniaefolia), jurema-preta (Mimosa tenuiflora), angico (Anadenanthera columbrina), leucena (Leucaena leucocephala) e acácia (Senna siamea) foram de 0,$13 ; 0,13 ; 0,17 ; 0,16$ e $0,23 \mathrm{~m}^{3} /$ ton, com média de $0,16 \mathrm{~m}^{3} /$ ton.

Segundo informações apresentadas pela SECTMA (2005), o consumo de lenha de PMF é de $0,36 \mathrm{~m}^{3}$ para produz uma tonelada de gesso. Com o uso de lenha em cavacos esse consumo foi reduzido a $0,15 \mathrm{~m}^{3} /$ ton de gesso produzido. 
TABELA 4: Análise de Variância do poder calorífico inferior dos clones de híbridos de Eucalyptus sp.

TABLE 4: Analysis of variance of the net heating value of the Eucalyptus sp. hybrid clones.

\begin{tabular}{ccccc}
\hline F. V. & G. L. & S. Q. & Q. M. & F \\
\hline Clones & 2 & 202471,2555 & 101235,6277 & $8,0961 *$ \\
Resíduo & 8 & 100033,3548 & 12504,1693 & \\
\hline Total & 10 & 302504,6104 & & \\
\hline
\end{tabular}

Em que: * significativo ao nível de $5 \%$ de probabilidade

TABELA 5: Comparação de médias do poder calorífico inferior pelo teste de Tukey dos clones de híbridos de Eucalyptus.

TABLE 5: Comparison of the net heating value by Tukey test clones of the Eucalyptus hybrid clones.

\begin{tabular}{cc}
\hline Trat/Clone & Média $(\mathrm{kcal} / \mathrm{kg})$ \\
\hline T15/C11 & $4.601,50 \mathrm{a}$ \\
T11/C41 & $4.481,63 \mathrm{a} \mathrm{b}$ \\
T7/C39 & $4.268,79 \mathrm{~b}$ \\
Média & $4.450,64$ \\
CV $(\%)$ & 2,52 \\
\hline
\end{tabular}

Em que: As médias seguidas pela mesma letra não diferem estatisticamente entre si o teste de Tukey ao nível de $5 \%$ de probabilidade.

Em termos médios, com o uso da lenha de eucaliptos em toras se conseguiu reduzir em 18,8\% o consumo de lenha quando comparado à lenha de sabiá, jurema-preta, angico, leucena e acácia, e em $63,9 \%$ quando comparado com o consumo de lenha oriunda de PMF.

\section{Área de reflorestamento para calcinação de gipsita com lenha em toras}

De acordo com o comportamento das curvas de IMA para os três híbridos (Figura 1) o ponto de máximo crescimento da floresta ocorreu entre quatro e cinco anos de plantio. Sendo assim, na simulação de quantos hectares seriam necessários para abastecer uma indústria de pequeno porte, foi considerada uma rotação de cinco anos com um IMA médio para os três híbridos de $28 \mathrm{~m}^{3} / \mathrm{ha}$.

Para um rendimento médio de $0,13 \mathrm{~m}^{3}$ de lenha com um teor de umidade médio de 19\% de umidade por tonelada de gesso produzida, a produção mensal de 2.000 toneladas seria atendida por $260 \mathrm{~m}^{3}$ de lenha/mês e a produção anual de gesso seria atendida por $3.120 \mathrm{~m}^{3}$ de lenha.

Diante dessas informações, pode-se estimar ser necessário o plantio de 22,3 hectares por ano, durante cinco anos, para que uma indústria, com produção média de 2.000 toneladas de gesso/mês, se torne autossustentável.

Considerando-se uma indústria abastecida por lenha oriunda de plantios de sabiá com IMA de $8,04 \mathrm{~m}^{3} /$ ha/ano, numa rotação de 6,5 anos e com um rendimento no forno de $0,13 \mathrm{~m}^{3}$ por tonelada de gesso, seria necessária uma área de plantio anual de $59,7 \mathrm{ha} /$ ano.

Abastecendo a indústria com lenha de um PMF com IMA de $4,5 \mathrm{~m}^{3} / \mathrm{ha} / \mathrm{ano}$, numa rotação de 10 anos e um rendimento de $0,36 \mathrm{~m}^{3}$ por tonelada de gesso, a área, sob plano de manejo florestal, necessária para atender à mesma produção de gesso, seria de 192,0 ha/ano.

Para tornar uma indústria de gesso autossustentável no consumo de biomassa florestal, a área sob plantio de sabiá, ou sob PMF, é 167,7 e $760,9 \%$, respectivamente, maior do que a área necessária quando comparada com a área de plantios de eucaliptos (Figura 2).

Levando-se em consideração que tanto o eucalipto como o sabiá podem ser manejados pelo regime de alto fuste e, posteriormente, por talhadia e que de acordo com Tewari et al. (2004), a taxa de crescimento de brotações nos três primeiros ciclos é superior à taxa de plantios de alto fuste, a quantidade de madeira produzida em 10 anos, tomando-se a rotação de um plano de manejo florestal como referência, seria de $280 \mathrm{~m}^{3} /$ ha para o eucalipto e de $80,4 \mathrm{~m}^{3} /$ ha para o sabiá, enquanto que a produção do PMF seria de $45 \mathrm{~m}^{3} / \mathrm{ha}$.

De posse dessas informações, pode-se afirmar que num período de 10 anos a quantidade de madeira produzida por hectare de eucalipto seria suficiente para produzir 2.154 toneladas de gesso, enquanto que um hectare plantado com sabiá equivaleria à produção de 618 toneladas, e numa área sob plano de manejo florestal a produção seria de 125 toneladas de gesso (Figura 3).

\section{Consumo de lenha em cavacos}

Assim como para o consumo de lenha em toras e quantidade de gesso produzida, as 
TABELA 6: Rendimento energético da lenha em tora de clones híbridos de eucaliptos na calcinação de gipsita nos fornos da Indústria Gesso Aliança do Araripe, em Trindade - PE.

TABLE 6: Energy efficiency of wood in logs of eucalyptus hybrid clones in the calcination of gypsum plaster kilns Industry Alliance of Araripe, in Trindade, Pernambuco state.

\begin{tabular}{ccccccc}
\hline $\begin{array}{c}\text { Trat / } \\
\text { Híbridos }\end{array}$ & $\begin{array}{c}\text { Duração da } \\
\text { fornada (min) }\end{array}$ & $\begin{array}{c}\text { Produção de } \\
\text { gesso (ton) }\end{array}$ & $\begin{array}{c}\text { Consumo de } \\
\text { lenha }\left(\mathrm{m}^{3}\right)\end{array}$ & $\begin{array}{c}\mathrm{m}^{3} / \text { ton } \\
\text { de gesso }\end{array}$ & $\begin{array}{c}\text { Teor de } \\
\text { Umidade (\%) }\end{array}$ & $\begin{array}{c}\text { Poder calorífico } \\
\text { útil (kcal/kg) }\end{array}$ \\
\hline T7/C39 & 127 & 5,8 & 0,90 & 0,16 & 21,95 & 3459,77 \\
T11/C41 & 110 & 5,4 & 0,57 & 0,10 & 14,70 & 3734,63 \\
T15/C11 & 125 & 5,4 & 0,68 & 0,13 & 19,36 & 3326,19 \\
Média & 120 & 5,3 & 0,72 & 0,13 & 18,67 & 3507,69 \\
\hline
\end{tabular}

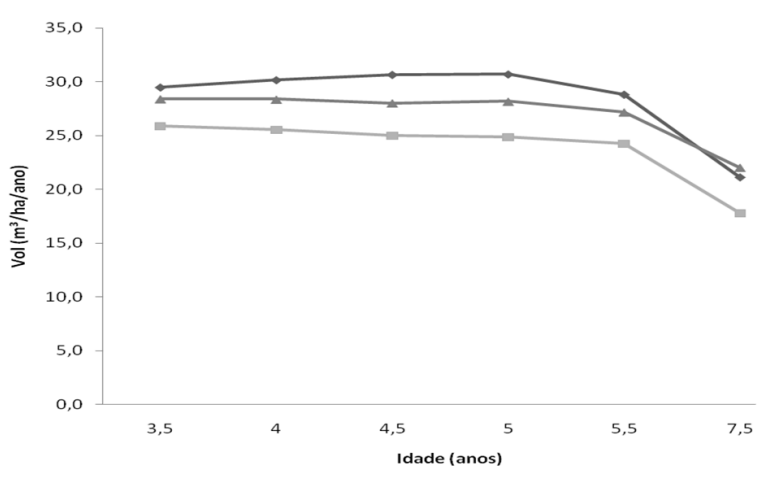

FIGURA 1: Curvas de incremento médio anual para os híbridos de Eucalyptus sp.

FIGURE 1: Mean annual increment curves for hybrids of Eucalyptus sp.

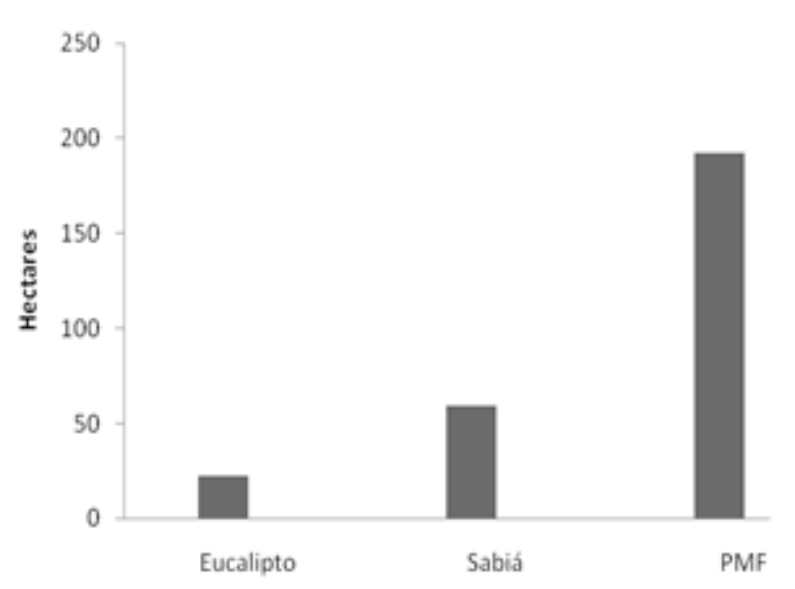

FIGURA 2: Área por ano, sob intervenção, necessária para atender à demanda de lenha de uma indústria de gesso com produção mensal de 2.000 toneladas.

FIGURE 2: Area per year under intervention needed to supply the demand for firewood from a plaster industry with monthly production on 2,000 tons.

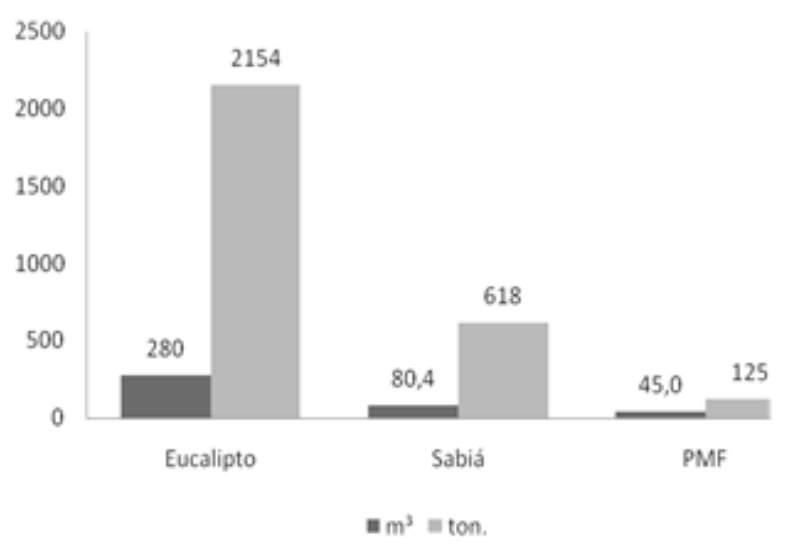

FIGURA 3: Volume de madeira e toneladas de gesso produzido em um hectare após 10 anos de exploração, utilizando lenha em toras.

FIGURE 3: Volume of wood and tons of gypsum produced in one hectare after 10 years of exploration, using wood in logs.

análises de variância não detectaram diferenças significativas, semelhante ao que ocorreu nos testes realizados na Indústria Gesso Aliança do Araripe Ltda. (Tabela 7), e as variações entre o consumo de lenha e a produção de gesso são justificadas pela condição de umidade do material no momento do teste.

De acordo com Ugulino e Queiroga (2008), o consumo de lenha picada de algaroba (Prosopis juliflora), nos fornos da indústria Gesso Aliança do Araripe, era de $0,15 \mathrm{~m}^{3}$ por tonelada de gesso. Após melhorias na forma de alimentação do forno o consumo, foi reduzido para $0,11 \mathrm{~m}^{3} / \mathrm{ton}$, e o tempo médio de uma fornada foi de 121 minutos, ou seja, $8,26 \%$ menor do que o tempo de calcinação com a lenha de eucalipto. 
TABELA 7: Rendimento energético da lenha em cavacos de clones de híbridos de Eucalyptus sp. na calcinação de gipsita nos fornos da Indústria Gesso São Geraldo, em Trindade - PE.

TABLE 7: Energy efficiency of wood chips in clones of Eucalyptus sp. hybrids in the calcination of gypsum plaster kilns Industry St. Geraldo in Trindade, Pernambuco state.

\begin{tabular}{ccccccc}
\hline $\begin{array}{c}\text { Trat / } \\
\text { Híbridos }\end{array}$ & $\begin{array}{c}\text { Duração da } \\
\text { fornada (min) }\end{array}$ & $\begin{array}{c}\text { Produção de } \\
\text { gesso (ton) }\end{array}$ & $\begin{array}{c}\text { Consumo de } \\
\text { lenha }\left(\mathrm{m}^{3}\right)\end{array}$ & $\begin{array}{c}\mathrm{m}^{3} / \text { ton } \\
\text { de gesso }\end{array}$ & $\begin{array}{c}\text { Teor de } \\
\text { Umidade (\%) }\end{array}$ & $\begin{array}{c}\text { Poder calorífico } \\
\text { útil }(\mathrm{kcal} / \mathrm{kg})\end{array}$ \\
\hline T7/C39 & 146 & 4,8 & 0,53 & 0,11 & 15,90 & 3774,59 \\
T11/C41 & 137 & 6,0 & 0,49 & 0,08 & 13,81 & 3779,69 \\
T15/C11 & 110 & 4,8 & 0,45 & 0,09 & 9,47 & 3807,71 \\
Média & 131 & 5,2 & 0,49 & 0,09 & 13,06 & 3791,03 \\
\hline
\end{tabular}

Segundo informações das indústrias Gesso São Geraldo e Gesso Aliança do Araripe, o consumo de lenha em cavacos oriunda de PMF é semelhante ao consumo da algaroba.

\section{Área de reflorestamento para calcinação de gipsita com lenha em cavacos}

Considerando uma fábrica em que os fornos operam apenas com lenha de eucalipto em cavacos, e com a mesma capacidade produtiva de 2.000 toneladas de gesso por mês, o consumo de lenha seria de $180 \mathrm{~m}^{3} /$ mês e $2.160 \mathrm{~m}^{3} /$ ano, quando o cavaco utilizado apresentar um teor de umidade médio de $13 \%$.

Para um povoamento com produtividade média de $28,0 \mathrm{~m}^{3} / \mathrm{ha} / \mathrm{ano}$, ao fim do ciclo de 5 anos, a produção seria de $140 \mathrm{~m}^{3} / \mathrm{ha}$, sendo necessário o plantio de $15,4 \mathrm{ha} /$ ano para atender à demanda de lenha da empresa.

Segundo Lima et al. (2005), a produção média de algarobais é de $62,42 \mathrm{~m}^{3} / \mathrm{ha}$, com rotação média de 12 anos, sendo o incremento médio anual de $5,2 \mathrm{~m}^{3} / \mathrm{ha} / \mathrm{ano}$.

Com o rendimento de $0,11 \mathrm{~m}^{3} /$ ton de gesso, o consumo mensal seria de $220 \mathrm{~m}^{3}$ e, anualmente, seriam consumidos $2.640 \mathrm{~m}^{3}$ de lenha de algaroba. Para atender a essa demanda a área necessária seria de 42,3 ha/ano.

Para a lenha de plano de manejo florestal com incremento de $4,5 \mathrm{~m}^{3} / \mathrm{ha} / \mathrm{ano}$, rotação de 10 anos e rendimento de $0,11 \mathrm{~m}^{3} /$ ton de gesso, a área utilizada sob PMF seria de 58,7 ha/ano.

Para uma calcinadora de gipsita de pequeno porte ser autossuficiente no seu abastecimento de lenha, a área sob plantio de eucaliptos equivaleria a $36,4 \%$ da área plantada com algaroba e quando comparada com a área de PMF seria equivalente a $24,6 \%$ (Figura 4 ).
Realizando a mesma simulação de produção de madeira e equivalência em toneladas de gesso produzida, também considerando a rotação de 10 anos como referência, a produção de lenha de eucalipto seria a mesma de $280 \mathrm{~m}^{3} /$ há, assim como a produção do $\mathrm{PMF}$ seria de $45 \mathrm{~m}^{3} /$ ha, e a produção da algaroba seria de $52,0 \mathrm{~m}^{3} / \mathrm{ha}$.

Para um consumo médio de $0,09 \mathrm{~m}^{3} /$ ton de gesso com o uso da lenha de eucaliptos, após 10 anos um hectare seria suficiente para produzir 3.111 toneladas de gesso. Já para um rendimento de 0,11 $\mathrm{m}^{3} /$ ton de gesso, para as lenhas de PMF e de algaroba, um hectare seria suficiente para produzir 410 e 472 toneladas de gesso, respectivamente (Figura 5).

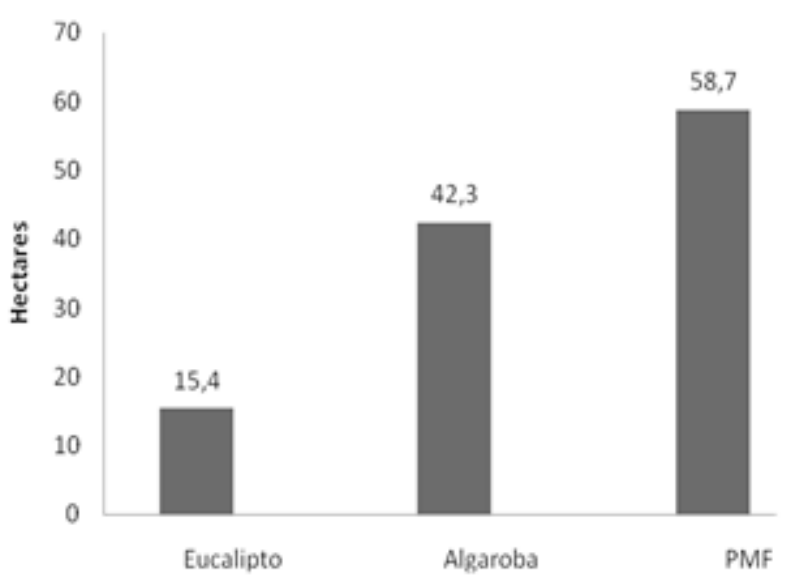

FIGURA 4: Área por ano, sob intervenção, necessária para atender à demanda de lenha em cavacos de uma indústria de gesso com produção mensal de 2.000 toneladas.

FIGURE 4: Area per under intervention needed to supply the demand for wood chips from a plaster industry with monthly production of 2,000 tons. 


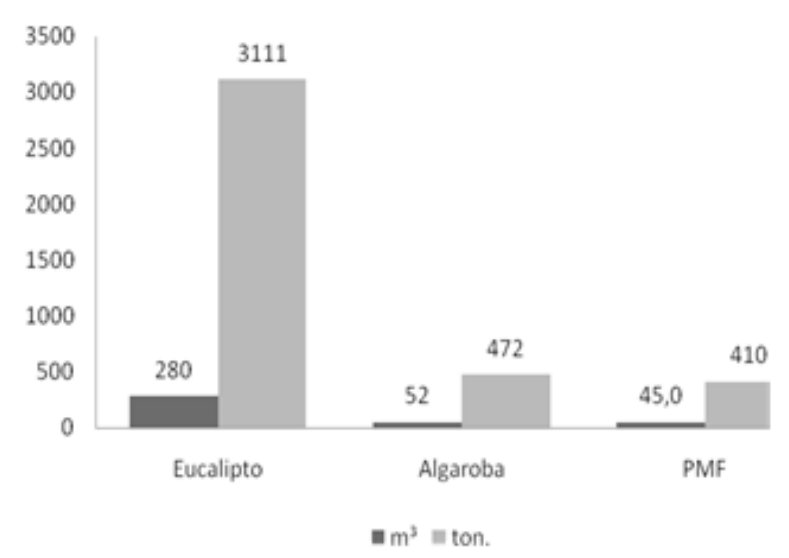

FIGURA 5: Volume de madeira e toneladas de gesso produzido em um hectare, após 10 anos de exploração, utilizando lenha em cavacos.

FIGURE 5: Volume of wood and tons of plaster produced in one hectare after 10 years of exploration, using wood chips.

\section{CONCLUSÕES}

$\mathrm{Na}$ avaliação do consumo de lenha em toras pelos fornos, observou-se uma redução de 18,8\% quando se comparou o consumo médio de lenha dos clones de eucaliptos, com o consumo médio de lenha das espécies estudadas por Barros (2009) e uma redução de $63,9 \%$ quando comparado com a lenha de PMF. Diante disso, estima-se que para atender à demanda de biomassa florestal de uma calcinadora, que produz em média 2.000 toneladas por mês de gesso e supondo que ela opere apenas com lenha de eucaliptos em toras com um teor de umidade médio de $19 \%$, seria necessário o plantio de 22,3 ha/ano, área essa equivalente a $37,4 \%$ de uma área plantada com sabiá e 11,6\% de uma área sob Plano de Manejo Florestal na Caatinga.

Já na avaliação do consumo de lenha em cavacos, observou-se que, na média, a lenha de eucaliptos apresentou um consumo 18,2\% menor que as lenhas de algaroba e de Plano de Manejo Florestal na Caatinga, podendo assim se estimar uma redução de $63,6 \%$ da área plantada, anualmente, para atender a uma indústria de pequeno porte, caso a indústria trabalhasse apenas com lenha de algaroba e em $73,8 \%$ acaso a indústria utilizasse apenas lenha de Plano de Manejo Florestal da Caatinga.

Comparando-se o consumo de lenha de eucaliptos em toras e em cavacos, observou-se uma redução de $30 \%$ de consumo quando se utilizou a lenha em cavaco, podendo assim estimar uma redução de 30\% de área plantada para atender a uma calcinadora.

Diante dos resultados apresentados, podese afirmar que a lenha de eucaliptos produzida na Chapada do Araripe apresentou melhor rendimento volumétrico e energético quando comparada às outras fontes de biomassa florestal usadas, atualmente, pelas calcinadoras.

Deve-se, ainda, considerar que áreas com algaroba e Plano de Manejo Florestal da Caatinga são manejadas com rotações de no mínimo 10 anos, enquanto que a rotação prevista para os eucaliptos avaliados é em torno de cinco anos. O que significa que em uma rotação de algaroba, ou PMF, acontecem duas rotações de eucaliptos, aumentando significativamente, a produção de madeira para atender à demanda do setor gesseiro.

Mesmo com uma produtividade abaixo da média nacional, povoamentos de Eucalyptus sp. na Chapada do Araripe têm plenas condições técnicas, econômicas e ambientais para atender à demanda por biomassa florestal na região, ocupando menores áreas que outros tipos de vegetação.

Quanto à escolha do melhor híbrido, recomenda-se trabalhar com os três, mesmo o C39 apresentando um rendimento menor. Pois na utilização de um só material genético e no caso do aparecimento de doenças ou pragas, o plantio ficaria muito suscetível, podendo ser perdida grande parte da produção de madeira.

Porém, até o momento não foi registrada a ocorrência de nenhuma doença ou praga de eucaliptos no local.

Por fim, por uma questão de conservação da vegetação nativa (caatinga) não se recomenda a prática do desmatamento de áreas, exploradas ou não pelo manejo florestal, para a implantação de povoamentos de eucaliptos, uma vez que a região possui 110.177 ha de áreas consideradas improdutivas para agricultura e pastagem, podendo essas serem utilizadas para o cultivo do eucalipto (SÁ et al., 2008).

\section{REFERÊNCIAS BIBLIOGRÁFICAS}

ALBUQUERQUE, J. L. Diagnóstico ambiental e questões estratégicas: uma análise considerando o Pólo Gesseiro do sertão do Araripe - Estado de Pernambuco. 2002, 185 f. Tese (Doutorado em Engenharia Florestal)-Universidade Federal do Paraná, Curitiba, 2002.

ALCORN, P. J. et al. Effect on initial planting density 
on branch development in 4-year-old plantation grown Eucalyptus pilularis and Eucalyptus cloeziana trees. Forest Ecology and Management, n. 252, p. 41-51, 2007.

ALVES, A. M. C. Quantificação da produção de biomassa e do teor de carbono fixado por clones de eucalipto, no pólo gesseiro do Araripe - PE 2007, 62 f. Dissertação (Mestrado em Ciências Florestais)Universidade Federal Rural de Pernambuco, Recife, 2007.

ARANGO ALZATE, S. B. A. et al. Variação longitudinal da densidade básica da Madeira de clones de Eucalyptus grandis Hill ex Maiden, E, saligna $\mathrm{Sm}$. e E. grandis $\times E$. urophylla. Scientia Forestalis, Piracicaba, n. 68, p.87-93, 2005.

ARAÚJO, S.M.S. NBR 11941: Densidade básica da madeira. Brasília: ABNT, 2003.

ARAÚJO, S.M.S. O Polo Gesseiro do Araripe: Unidades Geo-Ambientais e Impactos da mineração. 2004276 f. Tese (Doutorado em Ciências, Área de administração e política de Recursos Minerais)Universidade Estadual de Campinas, Campinas, 2004.

ASSOCIAÇÃO BRASILEIRA DE NORMAS TÉCNICAS. NBR 8644: Determinação do poder calorífico superior da madeira e do carvão vegetal. Rio de Janeiro, 1984.

ATECEL - Diagnóstico energético do setor industrial do pólo gesseiro da meso região de Araripina - PE. Campina Grande, 2006. 126 p.

BALLONI, E. A. et al. Produção de energia através de florestas de rápido crescimento. Piracicaba: IPEF, n. 103, p. 1-16, 1980.

BARROS, B. C. Volumetria, densidade, carbono e calorimetria de espécies nativas e exóticas no Pólo Gesseiro do Araripe. 2009. 67 f. Dissertação (Mestrado em Ciências Florestais)-Universidade Federal Rural de Pernambuco, Recife, 2009.

BINKLEY, D.; STAPE, J. L. Sustainable management of Eucalyptus plantations in a changing world. In: IUFRO CONFERENCE, 2004, Aveiro. Proceedings ... Aveito, 2004.

BORBA, R. S. et al. Crescimento do fungo simbionte de formigas cortadeiras do gênero Acromyrmex em meios de cultura com diferentes extratos. Ciência Rural, Santa Maria, v. 36, n. 3, p. 752- 730, 2006.

BRITO, J. O. et al. Análise da produção energética e de carvão vegetal de espécies de eucalipto. IPEF, Piracicaba, n. 23, p. $53-56,1983$.

CARVALHO, A. M.; NAHUZ, M. A. R. Valorização da madeira do híbrido Eucalyptus grandis $\times$ urophylla através da produção conjunta de madeira serrada em pequenas dimensões, celulose e lenha. Scientia Forestalis, Piracicaba, n. 59, p. 61-76, 2001.

COUTO, L.; MULLER, M. D. Florestas energéticas no Brasil. In: Tecnologias de conversão da biomassa. Manaus: EDUA/EFEI, 2000.

EMBRAPA SOLOS. Unidade de Execução de Pesquisa e Desenvolvimento do Recife. Solos do Nordeste. 2006. Disponível em: http://www.uep. cnps.embrapa.br/solos/index.html. Acesso em: 13 de julho de 2009.

GOMIDE, J. L. et al. Caracterização tecnológica, para produção de celulose, da nova geração de clones de Eucalyptus no Brasil. Revista Árvore, v. 29, n. 1, p. 129-137, 2005.

ITEP / LAMEPE. Médias históricas da chuva (mm) de janeiro a dezembro para o Estado de Pernambuco (1980 - 2008). Disponível em: http:// www.itep.br/LAMEPE.asp. Acesso em: 01 de novembro de 2009.

LIMA, P. L. F. et al. Manejo de áreas individuais de Algaroba. Projeto Manejo de espécies ameaçadas de extinção e de espécies invasoras, visando à conservação da diversidade biológica brasileira. Petrolina: MMA/ PROBIO/Embrapa Semi-Árido, 2005. (Relatório Final).

LYRA SOBRINHO, A. C. P. et al. Gipsita. Departamento Nacional de Produção Mineral. Disponível em: http://www.dnpm-pe.gov.br/, Acesso em: 09 de dezembro de 2007.

MACHADO, S. A.; FIGUEIREDO FILHO, A. Dendrometria. Curitiba: A. Figueiredo Filho, 2003. MMA (Ministério do Meio Ambiente)/SECTMA (Secretaria de Ciência Tecnologia e Meio Ambiente), Região do Araripe-Pernambuco. Diagnóstico florestal. Brasília, Ministério do Meio Ambiente, 2007, $91 \mathrm{p}$.

MORA, A. L.; GARCIA, C. H. A cultura do eucalipto no Brasil (Eucalypt cultivation in Brazil). São Paulo: Sociedade Brasileira de Silvicultura, 2000. $112 \mathrm{p}$.

MÜLlER, M. D.; COUTO, L. Avaliação de densidades de plantio e rotação de plantações de rápido crescimento para a produção de biomassa. Viçosa: RENABIO, 2006. 58 p. (Documento Técnico)

OLIVEIRA, A. D. et al. Avaliação econômica da vegetação de cerrado submetida a diferentes regimes de manejo e de povoamentos de eucalipto plantado em monocultivo. CERNE, Lavras, v. 4, n. 1 p. 34$56,1998$.

RIEGELHAUPT, E. Florestas nativas de produção 
no desenvolvimento florestal. Projeto GEF caatinga (MMA/GEF/PNUD), Araripe: Construção do Plano de Desenvolvimento Florestal do Araripe. 2007.

SÁ, I. B. et al. Potencialidades Florestais da Região do Araripe: uma abordagem utilizando técnicas de geoprocessamento e sensoriamento remoto. In: SIMPÓSIO REGIONAL DE GEOPROCESSAMENTO E SENSORIAMENTO REMOTO, 4., 2008, Aracaju. Anais... Aracaju, 2008.

SANTANA, W. M. S. Crescimento, produção e propriedades da madeira de um clone de Eucalyptus gradis e Eucalyptus urophylla com enfoque energético, 2009, 91 f. Dissertação (Mestrado em Ciência e Tecnologia da Madeira)-Universidade Federal de Lavras, 2009.

SECTMA. Polo gesseiro de Pernambuco: diagnóstico e perspectiva de utilização dos energéticos florestais na região do Araripe. Recife, 2005, 15 p.

SILVA, F. de A. S. e.; AZEVEDO, C. A. V. de. Versão do programa computacional Assistat para o sistema operacional Windows. Revista Brasileira de Produtos Agroindustriais, Campina Grande, v. 4, n. 1, p. 71-78, 2002.

SILVA, S. M. F .S. Comparação entre equações volumétricas regionais e equações baseadas em volume da primeira tora em clones de eucalyptus na chapada do Araripe-PE. 2008, 58 f. Dissertação (Mestrado em ciências Florestais)-Universidade Federal Rural de Pernambuco. Departamento de Ciência Florestal, 2008.

STURION, J. A. et al. Variação da densidade básica da Madeira de doze espécies de Eucalyptus plantadas em Uberaba-MG. Boletim de Pesquisa Florestal, Colombo, n. 14, p.28-38, 1987.

TEWARI, S. K. et al. Effect of age and season of harvesting on the growth, coppicing characteristics and biomass productivity of Leucaena leucocephala and Vitex negundo. Biomass and Bioenergy, v. 26, p. 229-234, 2004.

TRUGILHO, P. F. Densidade básica e estimativa de massa seca e de lignina na madeira em espécies de Eucalyptus. Ciência e Agrotecnologia. Lavras, v. 33, n. 5, p. 1228-1239, 2009.

UGULINO, S. M.; QUEIROGA, A. F. F. Relatório de implementação das opções $\mathbf{P}+\mathbf{L}-$ Gesso Aliança. CEPIS. Campina Grande, p. 1-23, 2008. (Relatório Final)

VITAL, B. R. Métodos de determinação da densidade da madeira. Viçosa: Sociedade de Investigações Florestais, 1984. 21 p. 